\title{
O TECNÓLOGO EM RADIOLOGIA E O MUNDO DO TRABALHO
}

\author{
Marlei Luiz Rodrigues Dourado ${ }^{1}$ \\ Mônica Bacelar Menezes²
}

\begin{abstract}
RESUMO
A presente pesquisa tem por objetivo discutir sobre a inserção do profissional do tecnólogo em radiologia no mercado de trabalho no Brasil através da investigação dos egressos do Curso Tecnológico de ensino superior em Radiologia e sua atuação profissional. Propõe-se analisar se o conhecimento construído pelo alunado atende as novas demandas do mundo do trabalho e a necessidade de profissionais qualificados para atenderem às inovações tecnológicas das empresas Nesta pesquisa é ressaltado os constantes desafios que serão encontrados e precisarão ser superados pelos futuros profissionais tecnólogos em radiologia e as estratégias para sua inserção e permanência no mercado de trabalho. Na investigação realizada foi aplicado o levantamento bibliográfico. Concluise que os futuros tecnólogos em radiologia precisam estar atentos a tudo que venha a ser: inovador, trasnformador e de grande valia para um maior e melhor aperfeiçoamento neste campo, contribuindo diretamente para o desenvolvimento de técnicas que venham a acrescentar para a área da saúde, que infelizmente encontra-se constantemente debilitada.
\end{abstract}

Palavras Chave: Tecnólogo. Radiologia. Trabalho. Entraves

\begin{abstract}
This research aims to discuss the insertion of the radiology technologist professional in the labor market in Brazil through the investigation of the graduates of the Technological Course of higher education in Radiology and their professional performance. It is proposed to analyze whether the knowledge built by the students meets the new demands of the world of work and the need for qualified professionals to meet the technological innovations of companies. radiology and the strategies for their insertion and permanence in the job market. Bibliographic survey was applied to the investigation. It is concluded that future technologists in radiology need to be attentive to everything that may be: innovative, transformative and of great value for a greater and better improvement in this field, contributing directly to the development of techniques that will add to the area of health, which unfortunately is constantly weakened.
\end{abstract}

Keywords: Technologist. Radiology. Job. Barriers

\section{Introdução}

O tema abordado nesta pesquisa se justifica pela necessidade tanto de analisar no mundo do trabalho, a empregabilidade do egresso do Curso Superior Tecnológico

\footnotetext{
${ }^{1}$ Mestre em Ciências da Educação pela Faculdade Interamericana de Ciências Sociais - FICS. Especialista em Bioimagem pela Faculdade Bahiana de Medicina e Saúde Pública. Tecnólogo em Radiologia pela Universidade Regional da Bahia - UNIRB. Bacharel em Administração com Habilitação em Análise de Sistemas pela Fundação Visconde de Cairu. Email: mlrdourado@hotmail.com

2 Mestra em Ciências da Educação pela Faculdade Interamericana de Ciências Sociais - FICS. Especialista em Anatomia Funcional pela Faculdade Futura. Especialista em Imaginologia com ênfase em Tomografia Computadorizada e Ressonância Magnética formada pela FATECI - Faculdade de Tecnologia Intensiva - CE; Tecnóloga em Radiologia Médica formada pela UNIRB - Faculdade Regional da Bahia - BA. Atualmente é professora da Faculdade de Tecnologia e Ciências- UNIFT- Salvador. Coordenadora de Estágio Supervisionado da UNIFTC. Professora da União Metropolitana de Educação e Cultura- UNIME. Professora Orientadora da Disciplina Estágio Supervisionado- UNIME. Coordenadora de Estágio do CST em Radiologia da União Metropolitana de Educação e CulturaUNIME. Email: monicabacelar.m@hotmail.com
} 
em Radiologia quanto identificar as competências trabalhadas no recém-formado avaliando se tais competências atendem às exigências das empresas para o acompanhamento das inovações tecnológicas.

A realidade da sala de aula é bem diferente do que é passado na prática e diante desta realidade faz-se necessário exercer uma heteronomia disfarçada de autonomia, já que as pessoas trabalham com um perfil diferente de discentes. Há de se entender as dificuldades de alunos que estão há muito tempo fora da sala de aula, e coordenar aquele aluno recém-formado do segundo grau, com ideias e conhecimentos recentes, porém sem nenhuma maturidade. Tudo isso sem perder o foco principal que é, no caso de um Curso Tecnológico, preparar e construir o profissional.

Dentro da literatura estudada, constata-se que há necessidade de pesquisas sobre o egresso do Curso Superior Tecnológico no mundo do trabalho no Brasil, pois aatualmente com o aumento da população, é grande a procura por Tecnólogo em Radiologia no país, ou seja, eles são cada vez mais necessários. Esse profissional que tem como principal objetivo contribuir na promoção, cultivo e restauração da saúde das pessoas. Existe a preocupação com a assistência, na promoção e na recuperação da saúde, bem como na prevenção de doenças. O profissional que almeja uma carreira bem-sucedida no setor necessita ser comprometido, ter controle emocional e investir em cursos de graduação e atualização constante.

\section{O Mundo do Trabalho}

O atual mercado de trabalho dispõe de um número considerável de profissionais tecnólogos, oferecendo às unidades de saúde o privilégio de escolher os mais habilitados. Dessa forma, os gestores de unidade de saúde elegem aqueles com melhor formação e maior experiência na profissão.

A qualidade profissional está pautada não apenas na habilidade técnica, que incide no treinamento e presteza para a concretização de procedimentos, mas na capacidade que esse profissional possui de utilizar e integrar seus conhecimentos em situações reais do cotidiano de forma ética e com base em evidências científicas.

Pode-se notar também que não basta apenas possuir todos os conhecimentos necessários para atuar na referida área profissional, mas também possuir um período considerável de experiências - e muitas vezes pode vir a fazer todo o diferencial - 
como também ter a capacidade de relacionar a ciência médica com o cotidiano das pessoas. No que se refere ao mundo do trabalho:

O mercado para o tecnólogo está crescendo, pois em função da formação mais ampla, possibilita o profissional a investir em educação continuada, com mestrado e doutorado. Também existem várias possibilidades de concursos públicos, bem como, o ingresso em empresas privadas (ARRUDA, 2018, p. 1).

Os cursos de graduação, pós-graduação, formações e os congressos são importantes tanto para ajudar o aluno a conhecer mais as oportunidades da profissão quanto para definir uma área de atuação. Essas aprendizagens podem levá-lo a ter uma compreensão mais completa, concreta e precisa a respeito da sua profissão abrindo caminho para as possibilidades em atuação e como este poderá ser destacar na sua área profissional, uma vez que:

O profissional precisa buscar o seu diferencial para conquistar espaço no mercado de trabalho. No entanto, saber atuar em diferentes áreas e com todos os tipos de imagens também é importante, pois os que tiverem maiores conhecimentos e técnicas são os mais requisitados (BADELLI, 2018, p. 1).

A autora aconselha que durante os anos de formação o aluno procure conhecer todas as áreas de atuação, seja em estágios ou vivências. Em suas abordagens procura apresentar a importância da atuação dos tecnólogos ressaltando diferentes aspectos relacionados à prestação de serviços dos mesmos.

A área da saúde necessita de uma atenção especial uma vez que a concepção, o desempenho e atuação dos tecnólogos, comprometem profundamente a qualidade da assistência proporcionada à população, pois tudo isso vem a refletir que tipo de profissional as instituições estão apresentando ao mercado de trabalho.

Ao discutir sobre as percepções frente às condições de inserção no mercado de trabalho ressalta-se as demandas vivenciadas no cotidiano profissional, identificando as características do mercado de trabalho para os futuros tecnólogos bem como o temor e o receio de enfrentar o competitivo mundo do trabalho (RODRIGUES, 2007).

Inserir-se no mundo do trabalho para qualquer profissional é um passo importante para o bom andamento do serviço, bem como para a satisfação profissional. A passagem da academia para o mundo de trabalho pode provocar períodos de insegurança pessoal no enfrentamento do "desconhecido" e na obrigação 
de se familiarizar com a nova aceitação, à medida que muitas vezes o "novo", em sua maioria causa espanto e insegurança, pois:

A transição da escola ao mundo do trabalho e o próprio processo de inserção profissional dos jovens transformou-se numa fase intermédia, num tempo de moratória, num verdadeiro percurso do combatente. É um dos principais problemas com que se debate a juventude contemporânea, sendo eleito para a intervenção pelos poderes públicos através de medidas de política de educação e formação profissional, de emprego e de juventude (CHARLOT; GLASSMAN, 1998, p. 21).

Mas para todo o profissional que galga oportunidades e realização dentro daquilo que buscou ser, é imprescindível ter foco, total dedicação e enxergar em cada situação que vivencie na sua profissão um novo e significativo aprendizado. $E$ em relação aos profissionais de tecnologia em radiologia, a sensação de responsabilidade torna-se mais ampla em decorrência de lidar com a vida e saúde das pessoas e a exaustiva carga horária de trabalho. E por serem recém-formados, os tecnólogos em radiologia no seu primeiro trabalho geralmente está relacionada a outros profissionais da equipe de radiologia, a médicos e até mesmo aos usuários dos serviços de saúde além de que:

O fenómeno social da passagem do sistema de educação/formação profissional para o sistema de emprego tem sido denominado de formas diversas: 'entrada na vida ativa', 'inserção profissional', 'entrada no emprego' e 'entrada no trabalho', 'transição para o trabalho', 'transição profissional', 'transição da escola para o trabalho', 'entrada na vida adulta' etc (ALVES, 2003, p. 48).

No começo das atividades profissionais o maior preconceito encarado referese à idade, na maioria por serem jovens e inexperientes, fazendo com que outros colegas de trabalho apresentem certa resistência em aceitá-los, não confiando no seu saber e habilidade. E essa situação precisa ser revista pois desta forma o futuro profissional muitas vezes passa por situações de desconforto e falta de apoio e incentivo por parte dos demais colegas.

\section{Tecnólogo X Biomédico}

O saber biomédico fundamenta-se em uma visão biológica e mecanicista do ser humano e na abordagem curativa das doenças e representa a visão oficial do corpo humano principalmente nas sociedades capitalistas aonde baseiam-se na capacidade de produção e de consumo. Tal saber é adquirido na academia e cursos da área com docentes preparados e especializados para contribuem para uma boa formação do futuro profissional que é influenciado não apenas as práticas objetivas 
de saúde, mas, também, a subjetividade das pessoas em relação ao seu corpo e à sua vida, ou seja, a relação entre: forma de viver e como isto se reflete no corpo e também mente de cada um.

Assim como o tecnólogo o biomédico vem a ser o profissional responsável por efetivar exames que autorizam o check-up por imagem, realizar análises de biologia molecular, averiguar e ampliar produtos obtidos por biotecnologias, manipular microrganismos para que seja possível industrializar como medicamento e realizar exames médicos em clínicas e hospitais para auxiliar a identificação de agentes causadores de patologias humanas, entre outras funções, pois:

O biomédico é responsável pela identificação, classificação e estudo dos microrganismos causadores de enfermidades. Ele desenvolve medicamentos e produz vacinas para combatê-las. Faz exames e interpreta os resultados de análises clínicas, para diagnosticar doenças e análises gramatológicas para verificar contaminações em alimentos (UNIVERSIA BRASIL, 2017, [s/p]).

A função do Biomédico é realização de exames de imagem, clínicos e de sangue, atuando na busca pelo diagnóstico de doenças. Ele em seu trabalho impacta vidas e sempre toma suas decisões pautadas na ética e responsabilidade. O biomédico é o profissional da área de saúde com formação superior em Biomedicina; tendo formação técnico-científica, com informação do organismo humano tanto nos seus feitios estruturais (células, tecidos e órgãos), quanto funcionais, investigando as interações tóxico-ambientais bem como os vetores e agentes causais das diversas doenças humanas (lbid.).

O campo de atuação do biomédico e do tecnólogo se assemelha no sentido de que ambos profissionais envolve toda a interconexão entre a medicina e a biologia. Eles estão aptos a ajudar na realização de exames, diagnóstico e avaliar as doenças, os agentes etiológicos e os vetores, sejam na atuação hospitalar ou na pesquisa, ajudando o médico radiologista com a leitura correta do exame para a emissão de laudos e pareceres concernentes aos diversos aspectos fisiopatológicos dos pacientes, além de realizar pesquisas para descoberta de novas doenças e novas curas.

O biomédico é conhecido pela sua atuação nas análises clínicas, embora o trabalho realizado por este profissional seja bastante amplo. Pois o mesmo ampliouse muito desde sua origem e deixou de ser um baluarte da medicina para tornar-se uma parte autônoma e bastante relevante. Os principais campos de atuação de um biomédico conforme Lima, (2016) estão exibidos no Quadro 1: 
Quadro 1 - Campos de Atuação de Um Biomédico

\begin{tabular}{|l|l|}
\hline $\begin{array}{l}\text { CAMPOS DE } \\
\text { ATUAÇÃO }\end{array}$ & \multicolumn{1}{|c|}{ ATIVIDADE REALIZADA } \\
\hline $\begin{array}{l}\text { Análises } \\
\text { clínicas }\end{array}$ & $\begin{array}{l}\text { Realizar análises, assumir a responsabilidade técnica e firmar os } \\
\text { respectivos laudos; tem competência legal para assumir e executar o } \\
\text { processamento de sangue, suas sorologias e exames pré-transfusionais; }\end{array}$ \\
\hline $\begin{array}{l}\text { Banco de } \\
\text { sangue }\end{array}$ & $\begin{array}{l}\text { Realizar todas as tarefas, com exclusão, apenas, de transfusão; tem } \\
\text { competência legal para assumir e executar o processamento de sangue, } \\
\text { suas sorologias e exames pré-transfusionais; }\end{array}$ \\
\hline $\begin{array}{l}\text { Biologia } \\
\text { Molecular }\end{array}$ & $\begin{array}{l}\text { Coleta de materiais, análise, interpretação, emissão e assinatura de laudos } \\
\text { e de pareceres técnicos; }\end{array}$ \\
\hline Genética & $\begin{array}{l}\text { Realizar exames de Citogenética Humana e Genética Humana Molecular } \\
\text { (DNA), realizando as culturas, preparações e análises; }\end{array}$ \\
\hline Docência & $\begin{array}{l}\text { Ministrar aulas para alunos de nível superior nas diversas instituições de } \\
\text { ensino do país, gerando assim, mais profissionais capacitados na área }\end{array}$ \\
\hline Estética & $\begin{array}{l}\text { Realizar procedimentos não-cirúrgicos. Ele necessita ter conhecimento de } \\
\text { anatomia, fisiologia, imunologia, biofísica, patologia e bioquímica. }\end{array}$ \\
\hline
\end{tabular}

Lima, (2016)

Verifica-se as mais diversas possibilidades ou campo de atuação do biomédico que possuem as mesmas qualificações do tecnólogo em radiologia com relação aos exames de imagem. E para tanto a participação de docentes tanto na graduação quanto em cursos de formação é imprescindível para obterem sucesso na profissão destacada acima.

\section{Possibilidades e Entraves Encontrados Pelo Egresso do Curso Superior Tecnológico em Radiologia no Mundo do Trabalho}

A transição do século $X X$ para o século $X X I$ ficou marcada por muitas transformações, mais especificamente no mundo do trabalho, o saber, inovações tecnológicas, novas formas de organização, e a crescente internacionalização e desterritorialização dos mercados (SCALON, 2009).

No Brasil, dentre as transformações que repercutiram no mercado de trabalho, podemos citar a flexibilização dos contratos, a precarização e uma significativa desindustrialização dos empregos, a qual derivou no crescimento de setores como o de serviços, o informal e o por conta própria (lbid.).

A crise enfrentada no Brasil nos últimos anos e as transformações ocorridas no desenvolvimento industrial do nosso país, houve a necessidade de mão-de-obra cada vez mais qualificada, exigindo assim uma adequação profissional às demandas do mercado, mostrando também entre outras coisas, as consequências de um grande impacto no mundo do trabalho, marcado por demissões crescentes e uma baixa de novos ingressantes com a carteira de trabalho assinada. Tal crise marcou e vem 
marcando todas as áreas da indústria que apontam para uma elevação constante na taxa de desempregados em diversas áreas, inclusive no campo da saúde, pois:

A recente, e duradoura crise econômica afetou diversas áreas e causou uma onda de desemprego no Brasil. No segmento da radiologia não foi diferente. A questão enfrentada por profissionais como auxiliares, técnicos e tecnólogos da radiologia é: como entrar e se manter no, cada vez mais exigente, mercado de trabalho (FALCO, 2018, p. 02).

No segmento da radiologia da mesma forma encontramos tais resultados, principalmente com o crescimento constante da tecnologia que vem substituindo cada vez mais os profissionais que operam as máquinas de ressonância magnética e Tomografia Computadorizada, por exemplo. O tecnólogo em radiologia atua em áreas mais complicadas e possuem possibilidade de melhores empregos, é uma profissão em desenvolvimento por causa do alto crescimento da tecnologia (SILVA et al., 2013).

E com o avanço da tecnologia faz-se necessário colocar como prioridade a qualificação profissional, visto que, como em todos os segmentos do mundo do trabalho, o profissional precisa acompanhar os avanços tecnológicos. Pois a técnica radiológica vem sofrendo grandes transformações, a área da saúde é a que encontramos os maiores métodos de diagnósticos, existem também o uso das radiações em terapia, área industrial, alimentícia etc. (NOBREGA, 2012).

Pode-se perceber que as tecnologias e as mudanças técnico-organizacionais dos processos de produção possibilitaram uma abertura para novos caminhos para conhecimento, no intuito de buscar responder de forma satisfatória as novas exigências do mercado. Assim, as possibilidades para o Tecnólogo em Radiologia crescem em consonância com os avanços tecnológicos obtidos na área.

O curso superior possibilita ao profissional a área de pesquisa, como mestrado ou doutorado. O tecnólogo também tem a chance de ingressos em concursos públicos e contratação em empresa privada. A sua área de atuação hoje em dia abrange muitos campos, pois:

\footnotetext{
O tecnólogo é um agente capaz de colocar a ciência e a tecnologia a serviço da sociedade. Atua-se em áreas mais complexas, possuindo maior variedade de emprego; profissão que ainda está em desenvolvimento. É um curso de nível superior, com foco na necessidade do mercado de trabalho (CARVALHO, et al. 2006, p. 39).
}

O profissional que apresentar além da graduação uma capacitação específica, provavelmente já está inserido no mundo do trabalho. Com a carga horária de 24 horas semanais esse profissional ainda consegue o ingresso em mais de um emprego, podendo ainda desfrutar da flexibilidade do tempo e partir para área 
acadêmica nos cursos técnicos e de graduação. O tecnólogo em radiologia atua em áreas mais complicadas e possuem possibilidade de melhores empregos, é uma profissão em desenvolvimento por causa do alto crescimento da tecnologia (SILVA et al., 2013).

É importante destacar as possibilidades que vão além da área médica. O profissional tecnólogo também está habilitado a trabalhar na indústria, utilizando fontes de radiação no controle de qualidade e em processos e serviços de segurança. Mais especificamente, nas indústrias alimentícias, através da irradiação de alimentos com finalidade sanitária, fotossanitária ou tecnológica e:

$\mathrm{Na}$ radiologia existe profissional de nível superior e nível técnico. Os tecnólogos são considerados nível superior e possuem uma ampla área de atuação sem precisar de especialização por possuir um amplo conhecimento sobre métodos de imagem (OLIVEIRA, 2007, p. 19).

A radiação também ganhou espaço nas engenharias, mensurando e diagnosticando possíveis rachaduras em estruturas metálicas e tubulações em edifícios. Pode-se também partir para a engenharia aeronáutica nas fuselagens de aeronaves e aviões, ou mesmo para empresas do Pólo Petroquímico, nos ensaios não destrutivos de caldeiras e peças afins uma vez que:

Os tecnólogos podem partir para atuar e se destacar na área industrial, para a atuação na mecânica ou auxílio na montagem de aeronaves e automóveis, indústria de alimentos, entre outros, com o importante papel de desempenhar a qualidade do produto (ANDREUCCI, 2006, p. 2).

A radiologia industrial é importante, pois informam as condições do interior dos materiais e qualidades de soldas. Deve ser devidamente controlada para diminuir riscos para trabalhadores, meio ambiente e população por decorrência da radiação ionizante.

O curso tecnológico tem duração de três anos apenas e consegue inserir no mundo do trabalho profissionais multi especializados com diversas possibilidades de atuação. A área médica foi o impulso para a evolução dos equipamentos e algumas destas foi aplicado na área industrial, envolve fontes radioativas, tubos de raios $\mathrm{X} e$ aceleradores de partículas. Um dos desafios encontrados pelos tecnólogos no mercado de trabalho se relaciona a situação ocupacional assumida pelos mesmos, que acabam por seguir funções que não são especificas perante a sua formação acadêmica (MARTINS, 2002).

Estes desempenham atividades profissionais que não são exclusivamente da sua formação acadêmica de tecnólogo. Desta maneira, é possível compreender que 
mesmo com uma formação específica e também com cursos de capacitação profissional na área, o mercado de trabalho no quesito empregabilidade ainda vem ser algo, que em determinado aspecto encontra-se um pouco tímido na perspectiva que ainda não corresponde para um quantitativo de vagas para estes profissionais. $E$ tal situação colabora para um declínio onde infelizmente os levam para exercer funções que não correspondem a sua formação. Vale destacar que:

Nem todos os jovens têm estratégias de inserção profissional "deliberadas", há os que têm "estratégias emergentes", ou seja, indivíduos cujas decisões em matéria de inserção profissional são tomadas em separado, não obedecendo a uma identificação de objetivos de longo prazo, mas em função dos constrangimentos, oportunidades e recursos disponíveis no momento (ALVES, 2003, p. 108).

O mercado atual está disputado, e cada dia mais difícil encontrar vagas, por isto há uma necessidade de uma boa qualificação em nível superior ou técnico, um bom profissional é aquele que busca conhecimento e atualidades. É importante que conheçam as Normas e Regulamentos ligados a sua profissão, pois são úteis ao dia a dia e se torna um diferencial (OLIVEIRA, 2007).

Torna-se importante que este profissional busque incessantemente sempre o estudo, análise situações, compreenda procedimentos e acima de tudo tenha em mente a importância da sua profissão para si mesmo e para as demais pessoas que precisam da eficiência do seu serviço, levando a uma significativa reflexão para sempre se reciclar.

Faz-se necessário perceber a importância de estar todo o tempo estudando para aprender a todo o momento e não cair no comodismo, como aquele que pensa que já sabe tudo e não possui mais nada a aprender. E ainda sim como esta é uma profissão que requer também lidar com o sentimento das pessoas que passam por momentos de fragilidade, o mesmo precisa ainda praticar a empatia, se colocar no lugar do outro para que em beneficio destes, todos os procedimentos que sejam necessários fazer, tragam resultados satisfatórios e ajudem de forma direta a todos.

\section{Graduação e o Mercado de Trabalho}

O curso superior de Tecnologia em Radiologia deve contemplar a formação de um profissional apto a desenvolver, de forma plena e inovadora, atividades relacionadas com o diagnóstico por imagem. Deve ter formação para a aplicação e o desenvolvimento de pesquisa e inovação tecnológica, difusão de tecnologias, gestão de processos de produção de bens e serviços, desenvolvimento da capacidade 
empreendedora e manutenção das suas competências em sintonia com o mundo do trabalho. Compreender o comportamento do mercado de trabalho é:

De grande importância para compreender o desempenho da economia, o volume de empregos criados, as taxas de desemprego e de aumento de produtividade, o montante de investimentos em treinamento e qualificação e muitas outras variáveis importantes que, juntas, determinam o desempenho econômico de um país ou região (BORGES, 1996, p. 19).

O nível de escolaridade da mão-de-obra constitui um indicador importante da qualidade da força de trabalho. No Brasil, o nível de escolaridade é tradicionalmente baixo. O conhecimento torna-se muito importante, sendo considerado um recurso indispensável, e jamais deixará de ser útil para a sua capacitação e vivência em sociedade. Pois o conhecimento vem a ser algo que ninguém pode tirar de outra pessoa, e "só através deste, o indivíduo poderá crescer, desenvolver e evoluir em muitos aspectos, tendo acesso a informações que terá valor significativo para a sua vida profissional“ (MOMM, 2004, p. 46).

Assim como o capital e os recursos naturais a mão de obra qualificada também deve ser considerada como um recurso econômico básico e essencial, aonde todos só tendem a ganhar. A procura de qualificação deve ser contrabalançada com a oferta de chances de cursos de formação apropriados às necessidades dos profissionais e de políticas públicas que tenham impactos no aumento no número de vagas disponibilizadas pelo mercado, para absorver a mão de obra. Vale destacar que:

\footnotetext{
Apesar de o desemprego atingir a todos, são os jovens que saem das universidades com toda disponibilidade de trabalho que enfrentam maiores dificuldades de colocação, haja vista a sua vulnerabilidade às adversidades do mercado de trabalho, em virtude de características como a falta de experiência e a busca por experimentação (ROCHA, 2008, p. 57).
}

As exigências, necessidades e regras que o mercado de trabalho impõe atualmente, a maneira mais viável de se conseguir chegar o mais próximo possível deste cenário é estar incluso, participando das obrigações e dos direitos de como deve ser um cidadão em um ambiente democrático.

É buscar cursar uma formação superior e profissional e entrar na fila para realizar as motivações, desejos e necessidades que o mundo econômico capitalista, individualista e competitivo divulga: ter emprego, casa, carro, poder viajar, e outras coisas que, aparentemente, são difundidas como sendo a felicidade. De modo a acompanhar as modificações constantes e a necessidade de adentrar no mundo do trabalho pode-se afirmar que: 
Transformações sociais como a liberalização econômica e a diversificação da mão de obra levaram a modificações profundas nas formas dos contratos sociais entre organizações e trabalhadores. Ocorreram demissões em massa, o emprego foi precarizado (temporário, por conta própria, partilhado, terceirizado, etc.), bem como se passou a exigir uma polivalência funcional (ROCHA- DE-OLIVEIRA; PICCININI, 2012, p. 67).

Essa é a realidade de milhões de brasileiros. As mudanças no mercado de trabalho têm afetado os trabalhadores quanto às exigências ao trabalhador. As organizações têm apresentado muitas variações ao longo do tempo. Fatores como: "o mundo em acelerada mudança, o impacto do desenvolvimento tecnológico, as novas formas de organização e configuração empresarial, novos produtos e serviços e novos processos de trabalho" (CHIAVENATO, 2014, p. 84).

O reflexo destas mudanças sobre a força de trabalho é que muitos trabalhadores ou ingressantes no mundo do trabalho apresentam deficiências em competências e habilidades para desempenhar atividades dentro das empresas. Desta forma, com a atual situação em que o país se encontra, para as pessoas conseguirem a inserção no mercado de trabalho, uma das melhores saídas para iniciar uma carreira profissional sólida e edificante a se fazer mesmo não sendo a certeza de empregabilidade imediata, é buscar ter uma graduação e/ou um curso técnico profissionalizante para ter maiores possibilidades de estar no meio profissional em que escolheu para a sua vida.

Para isso, os mesmos supracitados trazem maior preparo e visibilidade perante até mesmo no momento em que passa por um processo seletivo e eventual entrevista. Desta forma, entender o comportamento do mercado de trabalho, é de grande importância para compreender o desempenho da economia, o volume de empregos criados, as taxas de desemprego e de aumento de produtividade, o montante de investimentos em treinamento e qualificação e muitas outras variáveis importantes que, juntas, determinam o desempenho econômico de um país ou região indispensável (CAMARGO, 1996). Assim como o capital e os recursos naturais a mão de obra qualificada também deve ser considerada como um recurso econômico básico. O conhecimento torna-se muito importante e é considerado um recurso indispensável.

A procura de qualificação deve ser compensada com a oferta de oportunidades de cursos de qualificação correspondentes às necessidades dos trabalhadores e de políticas públicas que apresentem forças no aumento no número de vagas disponibilizadas pelo mercado, para absorver a mão de obra (MOMM, 2004). As 
mudanças no mercado de trabalho têm afetado os trabalhadores quanto às exigências ao trabalhador, pois:

As organizações têm apresentado muitas variações ao longo do tempo. Fatores como: o mundo em acelerada mudança, o impacto do desenvolvimento tecnológico, as novas formas de organização e configuração empresarial, novos produtos e serviços e novos processos de trabalho (CHIAVENATO, 2014, p. 84).

O reflexo destas mudanças sobre a força de trabalho é que muitos trabalhadores ou ingressantes no mundo do trabalho apresentam deficiências em competências e habilidades para desempenhar atividades dentro das empresas. $E$ dentro disto, é possível citar de maneira clara e objetiva o tecnólogo em radiologia, que de forma geral necessita estar focado em tudo o que a sua profissão exige e não bastando somente ser graduado por quê:

A qualificação profissional tem sido apontada como requisito para empregabilidade e vem constituindo-se como um desafio para aqueles que pretendem se inserir no mercado de trabalho. Os debates que envolvem as mudanças das relações laborais, principalmente a partir da década de 1990, têm sido pautados pelo destaque da necessidade de novos perfis profissionais que sejam capazes de dar conta desse novo contexto (LEMOS; DUBEUX; PINTO, 2009, p. 82).

O futuro profissional precisa estar preparado para enfrentar as demandas que a sua profissão exige e estar constantemente ligado a tudo aquilo que seja necessário para um maior e melhor atendimento a todos aqueles que necessitam de um profissional dedicado, responsável. Ele precisa estar comprometido com os seus afazeres e que busque também a satisfazer os anseios de pessoas angustiadas, tristes e também que não possuem conhecimento suficiente sobre esta função que vem se expandido cada vez no Brasil, mesmo com a crise de emprego e econômica que insiste em predominar em nosso país, algo que envolve diversos fatores.

Cada vez mais cada vez a vida empurra de forma árdua e complexa aqueles que buscam melhores condições de vida e o mínimo de conforto moral e social, para o mundo mais aprofundado dos estudos para um conhecimento cada vez mais completo consciente e determinante que poderá levar cada um para o caminho da realização, sucesso e progresso constante ou simplesmente para os que querem somente o comodismo de uma vida aparentemente sustentável.

A graduação e mercado de trabalho podem ser visto com um significado intenso que à luz de uma realidade pode-se perceber que cotidianamente traz para cada um a reflexão diária, na luta por uma situação favorável e tranquila em um mundo 
infelizmente individualista, cruel e devastador que traz consigo uma realidade difícil e que custa a muitos acreditarem e, ficando para atrás todos aqueles que não lutam por seus objetivos, não traçam metas e que mesmo a duras penas acreditam que somente através do conhecimento poderá destacar-se no mundo profissional.

É possível citar o questionamento levantado sobre a dificuldade dos profissionais saídos do ensino superior e se esses atendem às exigências do mercado de trabalho. O número de alunos graduados em tecnólogos de acordo com o Conselho Nacional de Educação aumenta cada dia como pode ser observado no Quadro 2 a seguir:

Quadro 2 - Relatório Técnico de Graduados no Curso de Tecnólogo de 1990 à 2011 RELATÓRIO TÉCNICO DO NÚMERO DE ALUNOS GRADUADOS EM TECNÓLOGOS DE 1990 À 2011

\begin{tabular}{|l|l|}
\hline Anos 90 & $\begin{array}{l}1.540 .080 \text { estudantes estavam matriculados no ensino superior no } \\
\text { Brasil. }\end{array}$ \\
\hline Em 2000 & $\begin{array}{l}2.694 .245 \text { estudantes estavam matriculados no ensino superior no } \\
\text { Brasil. }\end{array}$ \\
\hline Em 2011 & $\begin{array}{l}\text { 6.379.299 estudantes estavam matriculados no ensino superior no } \\
\text { Brasil. }\end{array}$ \\
\hline
\end{tabular}

Fonte: Ministério da Educação - Relatório Técnico, 2013

Observa que nas últimas décadas o Brasil acompanhou um crescimento significativo do ensino superior. Ou seja, é de se notar que houve um crescimento no número de matriculados e por consequência também no número de concludentes aptos a entrarem no mercado de trabalho, pois:

Entre a pessoa e a organização onde ela trabalha, existe uma verdadeira dinâmica que é fundamental para a obtenção dos objetivos tanto da organização como do empregado. Esta dinâmica é determinada pelas exigências do próprio trabalho e da organização e pelas demandas do empregado (PEIRO; PRIETO, 1996, p. 97).

Os melhoramentos para a organização manifestam-se na condição e na quantidade de trabalho realizado pelo empregado. As implicações para ele situam-se especialmente no grau da efetivação pessoal do contentamento, do bem-estar e da autoestima.

Desse modo compreende-se que a busca pela inserção no mercado de trabalho segue em uma via de mão dupla. Em uma via está a decisão a ser tomada no que se refere à escolha do curso superior que irá transformar a vida do profissional, na outra está à aceitação e o posterior reconhecimento desse profissional dentro do ambiente organizacional. 
Compreende-se também que essas decisões devem partir de um planejamento bem feito, tanto da parte do indivíduo que busca essa aceitação, quanto da parte das organizações que buscam profissionais bem preparados, em que se possam transferir as teorias aprendidas nas instituições de nível superior para a prática organizacional uma vez que:

O conhecimento é uma capacidade disponível em nós, seres humanos, para que processemos de forma mais adequada a nossa vida, com menos riscos e menos perigos. O conhecimento tem o poder de transformar a opacidade da realidade em caminhos "iluminados", de tal forma que nos permite agir com certeza, segurança e previsão (LUCKESI, 1985, p. 51).

Dessa forma, o próprio sistema capitalista continuará a criar abismos entre o profissional graduado e o mercado de trabalho, uma vez que é imprescindível identificar o caminho profissional daqueles que acabaram de sair da comunidade acadêmica, por que assim nos é permitido explorar, compreender e ponderar sobre os dilemas relativos ao ensino superior e as particularidades peculiares ao Mercado de Trabalho.

Há também as dificuldades relacionadas com os cursos de graduação escolhidos, consequentemente os novos profissionais surgem, mas não se desenvolvem, não estão preparados, logo não são absorvidos pelo mercado e assim sentem grande dificuldade em conseguir o primeiro emprego, independente da área de atuação ou do curso superior, uma vez que o fator determinante para o novo profissional é a experiência e para o mercado de trabalho são as regras e exigências já definidas por um mercado cada vez mais competitivo que requer a cada dia mais particularidades e talentos capazes de vencer os desafios impostos pela realidade global, onde a produção e os resultados estão em primeiro lugar.

Entende-se que, tanto os profissionais que concluíram o curso de nível superior, quanto as organizações interessadas em contratar esses profissionais devem ter em mente que necessitam quebrar as correntes que os prendem aos velhos paradigmas, e isto tem a ver com o envolvimento de ambas as partes, de uma forma que os resultados sejam favoráveis para as organizações e para os profissionais.

Os novos profissionais devem ter em mente que do momento da escolha do curso de nível superior até a tão almejada inclusão no mercado de trabalho, são várias etapas a serem vencidas e a mudança de mentalidade é uma das fases que requer enorme esforço. 
Atualmente existe um número cada vez maior de brasileiros chegando às salas de aulas das universidades e em cursos de pós-graduação. Na última década, o número de matrículas no ensino superior no Brasil dobrou, contudo, a decepção do mercado com o que está sendo chamado pela jornalista Costa (2013, versão on-line), em reportagem da $\mathrm{BBC}^{3}$ Brasil, de "a geração do diploma" é confirmada por especialistas, organizações empresariais e consultores de recursos humanos.

Ainda assim dentro do contexto profissional, pode-se citar algumas maneiras de conseguir a qualificação profissional, conforme Vidigal e Vidigal (2012) destacam na educação formal e na informal e cursos profissionalizantes e técnicos da seguinte forma:

> A educação formal é realizada por meio do aprendizado escolar e universitário, cuja atuação ocorre de forma intencional e com objetivos determinados;

> A educação informal, de modo divergente, é obtida por meio da observação, fora do sistema formal de ensino e até mesmo pela educação autodidata.

> Cursos profissionalizantes e técnicos: Essa forma de qualificação, bastante incentivada no Brasil, tem por características a curta duração e o rápido preparo técnico.

Assim, conforme as informações acima a respeito de se ter uma qualificação profissional, sejam cursos universitários e/ou ainda cursos técnicos profissionalizantes, é visível e indispensável na atualidade a importância em elevar o nível de formação e informação para maiores possiblidades para todos que buscam ingressar no mercado de trabalho que infelizmente tornou-se algo bastante competitivo algo que se atribui ao constante desenvolvimento das empresas em diversos aspectos.

O atual mundo do trabalho não aceita mais somente o básico e sim algo cada vez mais completo e rico em conhecimento, informação, domínio e capacidade para criar, desenvolver e transformar, na medida em que no contexto profissional e empregatício, as chances para quem se conscientiza que só através do estudo será possível conseguir um espaço profissionalmente serão maiores.

\section{Formação Continuada e Mercado de Trabalho}

\footnotetext{
${ }^{3}$ Corporação pública de rádio e televisão do Reino Unido fundada em 1922.
} 
Atualmente tem-se reconhecido que a formação inicial vem a ser apenas o primeiro passo no caminho da formação profissional e que, em virtude da provisoriedade do conhecimento, existe uma necessidade de uma formação permanente ou continuada e de o profissional adotar a postura de continuar a ser estudante e pesquisador. Assim, o indivíduo ao terminar a sua formação é integrado ao mercado de trabalho sendo necessário ter a capacidade de fazer frente a uma realidade muito exigente e rigorosa, assim, citamos a formação continuada como em qualquer profissão.

Os cursos superiores de tecnologia necessitam de constante reorganização e reelaboração e que devem ser interdisciplinares, propiciando uma construção de conhecimento contextualizado que dê significado ao aprendizado. Neste sentido, a utilização de metodologias que integre a vivência e a prática profissional mostra-se adequadas. Parte-se do pressuposto de que o exercício interprofissional é um imperativo para este século para o exercício do cuidado pleno e resolutivo em saúde (TAKAHASHI, 2010).

E para todos aqueles que buscam incessantemente qualificar-se para melhorar, destacar e ter uma maior e melhor estabilidade financeira vem a ser de fundamental importância, sendo uma extensão de tudo aquilo que conheceu, aprendeu e de certa forma vivenciou, na medida em que envolvem novos estudos, significativas pesquisas e exige constante dedicação. Assim, diversas profissões com conteúdos inovadores estão sendo criadas, visando acompanhar o ritmo das mudanças.

Transformações estruturais nas relações de trabalho também têm sido observadas. Sendo assim, a formação continuada para o tecnólogo em radiologia, também não foge dessas transformações e ligação direta com as atuais e novas tecnologias, que anda diretamente com este ramo de trabalho e que necessita do profissional supracitado sempre está atento a qualquer inovação, pois:

\footnotetext{
No passado, as pessoas concluíam seus cursos, chegavam ao mercado e, daí em diante, passavam o resto da vida consumindo e o conhecimento adquirido nos tempos de escola. Essa fase acabou; agora, passa-se o resto da vida adquirindo conhecimento. O mundo mudou o aprendizado não é mais estanque, datado; é contínuo, porque as técnicas, os métodos e os processos alteram-se sistematicamente. Essa realidade passa a fazer parte da vida (TREVISAN, 2000, p. 89).
}

Pode-se afirmar que é de grande relevância a busca pelo conhecimento e educação continuada, porque é como uma parceria para o sucesso e que as atribuições dos docentes não é apenas instruir e capacitar os indivíduos. 
É fundamental a interação de alunos e docentes do curso de tecnologia em radiologia com o campo de trabalho visando à construção do conhecimento e aprimoramento da formação do profissional por meio da extensão, realizando pesquisa e aprofundando o ensino. A deficiência de aulas práticas representa, sem dúvida, a queixa com maior tenacidade entre os graduados e graduandos do curso de tecnologia em radiologia (ALEXANDRINA et al.2012).

Compreende-se que os educadores têm a responsabilidade de incentivá-los a buscar o conhecimento necessário para que durante o curso e após a formação universitária os egressos tenham as habilidades necessárias para fazer a integração entre a teoria e a prática. Tudo isso no intuito de aumentar o conhecimento a respeito da área em que está inserido, atuando, tornando-se importante conhecer a trajetória da evolução profissional desta, pois:

A educação superior se torna um elo importante na cadeia de esforços do processo educativo e organizacional, onde pensar em conhecimento num mundo capitalista não é se referir a qualquer conhecimento. É como fazer ciência para todos diante de um cenário cada vez mais elitista, individualista e divisor, no qual a desigualdade cresce em ritmo acelerado (PRAHALAD, 2010, p. 12).

O ensino superior não pode ser visto como uma operação comercial, onde as instituições de ensino competem entre si na busca de educandos com ofertas aparentemente excepcionais. Elas devem oferecer um ensino de qualidade e dar um preparo adequado às inspirações dos alunos, e isto é o mínimo que as organizações que irão absorver esses profissionais esperam.

Essas organizações são altamente competitivas $e$ isso demanda grande competência deste profissional que necessitará comprovar suas aptidões. Desta forma, como o próprio nome já diz, a formação continuada vem a ser de extrema importância à medida que possibilita agregar maiores conhecimentos e informações pertinentes a sua profissão.

Isso faz com que cada um se aprimore e melhore a sua atuação no seu respectivo setor profissional, dominando cada vez mais com competência e objetividade sua função e destacando-se no mercado de trabalho, criando meios que o leve ao crescimento e se tornando alguém realizado, satisfeito e com vontade de contribuir para inovação, transformação e expansão para empresa a qual presta serviços.

Frente ao século XXI, o mercado de trabalho exige de forma direta diante de tantas modificações que acontecem a todo o momento, profissionais com bagagem 
suficiente para destacar-se e fazer a diferença perante os demais profissionais, que sejam proativos e que enxerguem além daquilo que vem a ser pensado e desejado.

É imprescindível estar sempre à frente de tantos outros, mostrando-se alguém versátil, inteligente e com capacidade para gerir uma equipe e/ou ainda ter conhecimento suficiente a respeito de tudo e todos aqueles que convivem consigo cotidianamente. Assim, frente às necessidades que o mercado de trabalho vem exigindo aos profissionais em suas respectivas áreas o tecnólogo em radiologia, precisa atualizar-se constantemente acerca do conhecimento teórico e uma formação humana cada vez mais ampla, por quê:

Os setores de diagnóstico por imagem e de radioterapia estão muito interessados em profissionais desta forma, que pesquisam, questionam e não se cansam em procurar tudo aquilo essencial para o seu crescimento, desenvolvimento e que contribua de forma muito significativa para a área em que se encontra (BOÉCHAT et al 2009).

Essas condições mercadológicas atribuir ao tecnólogo em radiologia um delineamento substancial que relaciona funções e habilidades importantes no que se refere a produção de imagens nos diversos equipamentos da área de Radiologia realizando atendimento ao cliente de modo eficiente mantendo a ética (UNCISAL, 2006; CEFET, 2014).

Sendo assim mediante a tudo o que vem sendo discutido e trazido dentro do contexto da formação continuada, pode-se perceber que a mesma vem a ser de grande relevância para o profissional à medida que traz para os mesmos informações mais consistentes e benéficas.

Pois enriquece a sua prática, abre caminhos perante a tantas transformações tecnológicas e mostra muitas vezes o despreparo em que sai os estudantes recémformados com uma deficiência considerável muitas vezes levando-se em conta o currículo, como por exemplo, a insuficiência de carga horária em atividades de estágio com especial destaque para a área de urgência/emergência bem como na aprendizagem de uma gama maior de diagnósticos por imagem.

\section{Considerações Finais}

Após toda a pesquisa pode-se afirmar que para o profissional tecnólogo em radiologia adentrar no mercado de trabalho no Brasil necessita de uma boa formação acadêmica e também de formação continuada no ramo de atuação. As mudanças na formação do trabalho, que ocorrem ao longo dos tempos e que distinguem o 
movimento de reestruturação produtiva, refletem em novos cenários do mercado de trabalho, exigindo novas e algumas características dos profissionais que neles se colocam e almejam continuar produtivos.

Faz-se necessário que os egressos tecnólogos em radiologia procurem se capacitar para estarem mais habilitados e com poder de disputar por melhores condições de trabalho em espaços cada vez mais diversos na área da saúde. Pois $E$ a área da saúde é merecedora de uma atenção especial uma vez que, a formação, o desempenho e a gestão dos recursos humanos, afetam profundamente a qualidade da assistência prestada à população.

Para esses profissionais o mercado de trabalho atualmente apresenta-se em grande crescimento, de maneira especial tendo em consideração apreço as três grandes áreas de atuação: o gerencial, o assistencial e a docência. Necessitando que o mesmo atenda a tais expectativas e busque posicionar-se de modo responsável pela assistência, agir na prestação de serviço na sua área específica de atuação, no setor de planejamento, realizando ou ajuizando as atividades de rotina ou de alta complexidade que demandam o trabalho direto como profissional, atendendo o que estabelece a Lei do Exercício Profissional do tecnólogo em radiologia.

A qualidade profissional está pautada não apenas na habilidade técnica, que incide no treinamento e presteza para a concretização de procedimentos, mas na capacidade que esse profissional possui de utilizar e integrar seus conhecimentos em situações reais do cotidiano de forma ética e com base em evidências científicas.

Ao final aborda-se que esta pesquisa gera contribuições profícuas promovendo expectativas sobre novas pesquisas realizadas com dados mais específicos que, possam servir como base de referência para futuras avaliações sobre o tema pesquisado que foi a inserção do tecnólogo em radiologia no mercado de trabalho. Transporta-se até os dias de hoje dúvidas em relação à eficiência em resolver problemas socioeconômicos como a desigualdade (aplicada a todos os gêneros) e o desemprego, que são marcas registradas em nosso país, mesmo depois de tantos anos e tantas Constituintes subsequentes.

\section{REFERÊNCIAS}

ALEXANDRINA, J. et al. O ensino, a pesquisa e a extensão na formação do tecnólogo em radiologia do IFSC. Santa Catarina: Revista Técnico Científica (IFSC), 2012. 
ANDREUCCI, R. Iniciação á Radiologia Industrial. Três Lagoas: Playimagem, 2006.

ARRUDA, S. M. B. O mercado de trabalho do tecnólogo em Radiologia em discussão. Mesa Redonda Atuação do Tecnólogo em Radiologia. 1ำ Congresso em Radiologia. Paraná, 2018.

ALVES, M. A inserção profissional de diplomados de ensino superior numa perspectiva educativa: o caso da faculdade de ciências e tecnologia. Lisboa: F.C.T. U. L, 2003.

BADELLI, J. O mercado de trabalho do tecnólogo em Radiologia em discussão. Mesa Redonda Atuação do Tecnólogo em Radiologia. 1ํㅡㄹ Congresso em Radiologia. Paraná: Rev. Brasil, 2018.

BOÉCHAT A.L.; SOUZA E.G.; MOREIRA F.A., et al. Proposta de um programa básico para a formação do médico residente em radiologia e diagnóstico por imagem. São Paulo: Radiol Bras, 2009.

BORGES, J. C. A Qualificação Profissional do Trabalhador para o Mercado de Trabalho e Ambiente Organizacional. Taquara - Rio Grande do Sul: FACCAT, 1996.

CAMARGO, J. M. Flexibilidade e produtividade do mercado de trabalho brasileiro. In CAMARGO, J. M. (Org.). Flexibilidade do mercado de trabalho no Brasil. Rio de Janeiro: Editora Fundação Getúlio Vargas. 1996.

CARVALHO, A; KIENBAUM, D; MEWS, M; STEFFEN. R. Tecnólogo: um profissional emergente no ambiente competitivo. Três Lagoas-MS: Conexão, 2006.

CEFET. Perfil do curso de tecnologia em radiologia para divulgação à comunidade. Minas Gerais: CEFET, 2014.

CHARLOT, B.; GLASMAN, D. (Org.). Jovens, integração, emprego. Paris: PUF, 1998.

CHIAVENATO, I. Gestão de Pessoas: o novo papel dos recursos humanos nas organizações. Barueri: Manole, 2014.

FALCO, V. Mercado de trabalho: o novo profissional de radiologia. 5a Região. São Paulo: CRTR. 2018.

LEMOS, A. H. C.; DUBEUX, V. J. C.; PINTO, M. C. S. Educação, empregabilidade e mobilidade social: convergências e divergências. Rio de Janeiro: Cadernos EBAPE. BR, 2009.

LIMA, R. A Importância do Profissional de Biomedicina. Rio de Janeiro: Guanabara Koogan, 2016.

LUCKESI, C. C. Fazer universidade: uma proposta metodológica. São Paulo: Cortez, 1985. 
MARTINS, C. B. Notas Sobre o Ensino Superior Brasileiro. Brasília, 2002.

MOMM, L. Mercado de Trabalho e Desemprego: oferta e demanda de emprego via Internet, uma nova tendência. Estudo de caso no Banco Nacional de Empregos. BNE. Florianópolis: UFSC, 2004.

NOBREGA, A. I. Tecnologia radiológica e diagnóstico por imagem. 5 ed. São Caetano do sul, SP: Difusão editora, 2012.

OLIVEIRA, S. Ser tecnólogo é válido? Revista EXAME: Grupo, 2007.

PEIRÓ, J.M.; PRIETO, F. Tratado de Psicologia do Trabalho. Madri: Editorial Síntesis, 1996.

PRAHALAD, C. K. A atividade dos gerentes da Nova Era no emergente panorama competitivo, in: A Organização do Futuro: Como preparar hoje a empresas do amanhã. São Paulo: Revisão 3. ed. Futura Foundation, 2010.

ROCHA, S. A inserção dos Jovens no mercado de Trabalho. Salvador: Cadernos CRH. 2008.

ROCHA-DE-OLIVEIRA, S.; PICCININI, V. C. Uma Análise Sobre a Inserção Profissional de Estudantes de Administração no Brasil. Porto Alegre :Revista de Administração Mackenzie, 2012.

RODRIGUES, P. A. Tecnólogo em Desenvolvimento de Software. Rio de Janeiro: Campus/ Elsevier, 2007.

SCALON, M. C. Estrutura Social e Mobilidade: uma análise da década de 90. In: Ensaios de Estratificação. Belo Horizonte: ARGVMETVM, 2009.

SILVA, J. L. F.; MAFFALDA, H. R.; FILONI, E. Empregabilidade do profissional formado no curso superior e tecnólogo em radiologia e suas áreas de atuação. Três Lagoas, MS: Rev. Conexão Eletrônica, 2013.

TAKAHASHI, A. R. W. Cursos superiores de tecnologia em gestão: reflexões e implicações da expansão de uma (nova) modalidade de ensino superior em administração no Brasil. Rio de Janeiro: Revista de Administração Pública, 2010.

TREVISAN, A. M. Empresários do Futuro: Como os jovens vão conquistar o mundo dos negócios. 4. ed. São Paulo: Editora Infinito, 2000.

UNIVERSIA BRASIL. Como conseguir um trabalho melhor. São Paulo: Universia Brasil, [on line], 2017.

VIDIGAL, C. B. R.; VIDIGAL, V. G. Investimento na qualificação profissional: uma abordagem econômica sobre sua importância. Taquara - Rio Grande do Sul: FACCAT, 2012. 